\title{
Thyroid Replacement Therapy: The Hidden Challenges
}

\author{
Asad Rahim ${ }^{\mathrm{a}}$, Stephen Goundrey-Smith ${ }^{\mathrm{b}, \mathrm{c}}$
}

\begin{abstract}
Hypothyroidism has a gradual onset and non-specific symptoms, which might be subtle, and which might therefore be ignored or misdiagnosed. Subclinical hypothyroidism is a well-established phenomenon where a patient does not have thyroid symptoms, but shows biochemical evidences of hypothyroidism. However, diagnosis and treatment of these patients may prevent development of overt hypothyroidism and cardiovascular symptoms. Replacement therapy with levothyroxine (T4) is the treatment of choice for hypothyroidism; levothyroxine is taken daily, provides stable plasma levels and is suitable for the majority of patients. Patients with certain forms of hypothyroidism - central hypothyroidism, thyroidectomy patients and patients with "low T3 syndrome" - may benefit from treatment with liothyronine (T3), which is more potent and has a shorter onset of action. The use of liothyronine in combination with levothyroxine is controversial, but there is evidence that some patients, particularly those with deiodinase 2 and thyroid hormone transporter expression polymorphisms, may benefit from combination therapy.
\end{abstract}

Keywords: Hypothyroidism; Liothyronine; Levothyroxine; Subclinical hypothyroidism

\section{Introduction}

Hypothyroidism is a condition with a gradual onset and

Manuscript accepted for publication December 19, 2013

\footnotetext{
${ }^{a}$ Birmingham Heartlands Hospital, Heart of England NHS Foundation Trust, Bordesley Green E, Birmingham, West Midlands B9 5SS, UK ${ }^{b}$ PDC Healthcare Ltd, Wilson House, Leicester Road, Ibstock, Leicestershire LE67 6HP, UK

${ }^{c}$ Corresponding author: Stephen Goundrey-Smith, PDC Healthcare Ltd, Wilson House, Leicester Road, Ibstock, Leicestershire LE67 6HP, UK. Email: stephen@the-pdc.com
}

doi: http://dx.doi.org/10.4021/jem200w non-specific symptoms, and is associated with significant morbidity and co-morbidity. The prevalence of spontaneous hypothyroidism is $1-2 \%$ [1] affecting women 10 times more frequently than men, and being more common in older women. In areas where iodine deficiency is not a problem, autoimmune disease is usually responsible (atrophic or Hashimoto's thyroiditis), but other significant causes include treatment of hyperthyroidism [1].

The symptoms of hypothyroidism tend to be non-specific and may initially be very subtle and therefore misdiagnosed, for example as depression, or even ignored. Those of greatest diagnostic value include cold intolerance, weight gain, tiredness, impaired cognition, constipation, reduced sweating with dry skin and hair and generalised muscular aches and paresthesia. Physical signs in overt cases typically include periorbital puffiness, cold skin, hoarse voice, slow pulse and slowing of the recovery phase of ankle jerk reflexes. In extremis, patients may present with confusion, impaired intellect and dementia (myxoedema madness) or myxoedema coma (with hypothermia) [1].

\section{Diagnosis of Hypothyroidism}

Many of the symptoms of hypothyroidism are not specific for the disease, with some present in a significant proportion of euthyroid subjects and therefore hypothyroidism cannot be diagnosed accurately on symptoms alone [2]. The diagnosis of hypothyroidism must be based on the finding of abnormal thyroid function test results. It is accepted that a TSH level greater than $10 \mathrm{mU} / \mathrm{L}$ combined with a free $\mathrm{T} 4$ level below the reference range indicates the presence of overt primary hypothyroidism requiring [3-5]. A TSH concentration above the reference range together with normal free T4 level is defined as subclinical hypothyroidism. Such cases of subclinical hypothyroidism require confirmation at least $3-6$ months after the initial results in order to exclude transient causes of a raised TSH especially. Subclinical hypothyroid patients who are antithyroperoxidase antibody (TPOAb) or antithyroglobulin antibody $(\mathrm{TgAb})$ positive are more likely to have higher serum TSH $[6,7]$, and more likely to develop overt hypothyroidism, but do not have an increased mortality rate 


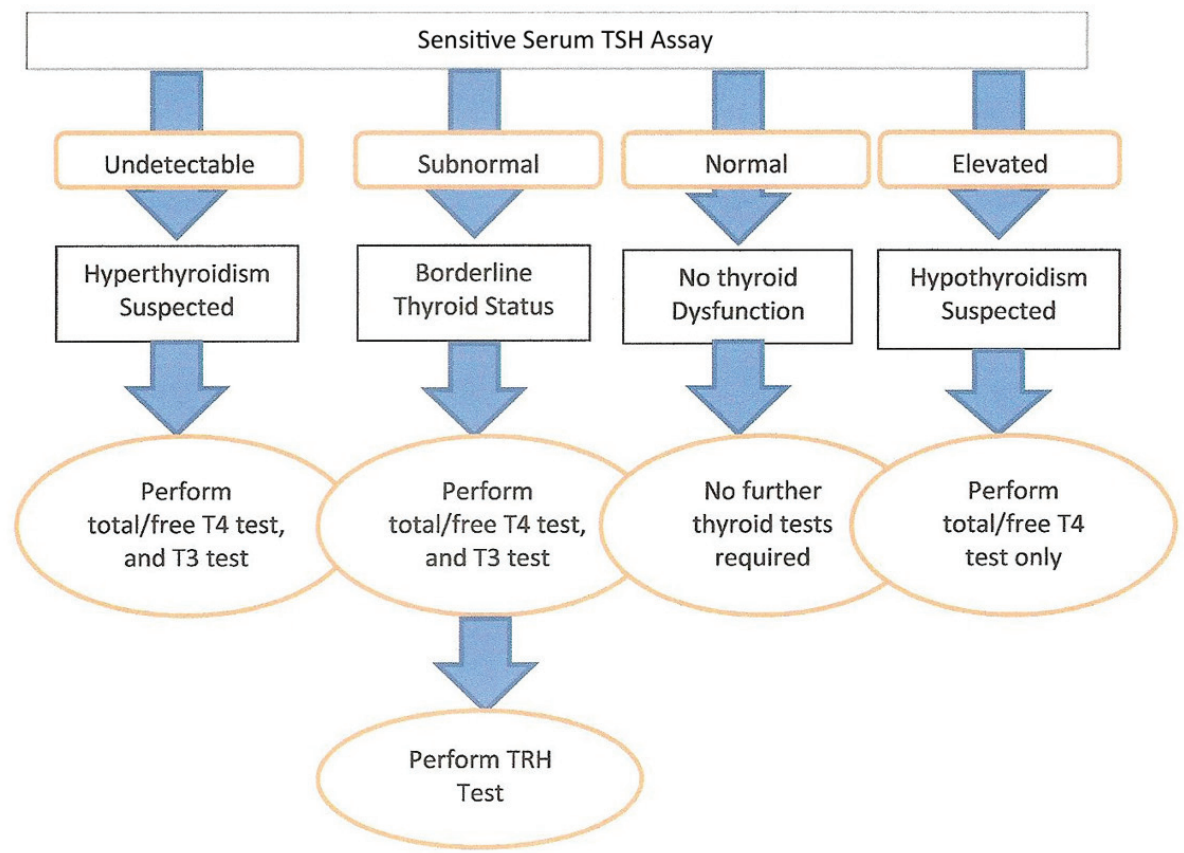

Figure 1. The procedure for laboratory investigation of thyroid function.

or higher incidence of ischemic heart disease $[8,9]$. The procedure for laboratory investigation of thyroid function(Fig.

1) $[5]$.

\section{Systemic Effects of Hypothyroidism}

\section{Heart}

Hypothyroidism is associated with both functional and atherosclerotic changes of the heart. Those with hypothyroidism may demonstrate impaired endothelial function, impaired left ventricular diastolic dysfunction at rest and elevated diastolic and systolic blood pressure on exercise. These endpoints are thought to be due to increased systemic vascular resistance and ultimately may result in poor physical exercise capacity. These abnormalities are reversible with T4 replacement therapy. An increased risk of atherosclerosis is demonstrated from autopsy findings as well as from epidemiologic data [10].

\section{Brain}

Various abnormalities in brain function, including cognitive and memory impairment in hypothyroid patients are now well established as reduced levels of thyroid hormone are associated with slow serotonergic neurotransmission in the brain [11], an effect associated with low mood. Moreover, differences in free T4 and TSH concentration, even within the reference range, may determine psychologic well-being in treated hypothyroid patients [12].

\section{Thyroid Hormone Secretion}

The thyroid secretes a total of $80-100 \mu \mathrm{g}$ of T4 and T3 on a daily basis; T4 is secreted in far larger amounts than T3, with a ratio of approximately 20-30:1 respectively. In plasma, free hormone is in equilibrium with protein-bound hormone, with $1 / 3,000$ of T4 being in a free state. However, it is T3 which is the active form of the thyroid hormones in tissues and is 3-5 times more active than T4. Of the T3 in tissues, $90 \%$ is derived from T4. Indeed $80 \%$ of T4 is de-iodinated to provide $90 \%$ of the free $\mathrm{T} 3$ needed by tissues. Thus the management of hypothyroidism has been focused on T4 replacement [13].

\section{Treatment}

Standard treatment of hypothyroidism is with levothyroxine [13]. This is normally taken in the morning $30 \mathrm{~min}$ before breakfast to prevent malabsorption that may occur if taken with food [14]. More recently, administration of levothyroxine before bedtime has been studied. This strategy has been shown to improve TSH, free T4 and free T3 levels, but none of these changes have been shown to impact quality of life, lipid profile or blood pressure [15].

Several medications, supplements and food can interfere with the absorption and action of levothyroxine. Iron and calcium are particularly common supplements and levo- 
thyroxine should be taken at least $4 \mathrm{~h}$ apart from these drugs. Enzyme inducers, such as phenytoin and carbamazepine, may increase the metabolism of levothyroxine and therefore result in increased effect of levothyroxine. Inadequate levothyroxine dose, poor compliance with medication (biochemistry usually showing high TSH with normal free T4), malabsorption and coexisting celiac disease or autoimmune gastritis may also interfere with achieving a biochemical euthyroid status [16].

Subclinical hypothyroidism is a well-established clinical entity where patients may not have overt symptoms of hypothyroidism, but have biochemical evidence of hypothyroidism. Some commentators have suggested that subclinical hypothyroidism should be treated only in certain situations. However, Sharma et al have noted that the diagnosis and treatment of subclinical hypothyroidism may prevent progression to overt hypothyroidism and cardiovascular disease [17]. In other words, the relatively inexpensive treatment of hypothyroidism may avert the need to treat cardiovascular complications, which would be more costly in terms of hospitalization and patient morbidity/mortality [18]. Also, some seriously ill patients have reduced levels of circulating thyroid hormones, which has been termed non-thyroidal illness syndrome (NTIS) [19], and thought to be related to the role of deiodinases in systemic disease and granulocyte function. This is an area where thyroid hormone modification may have a role.

Levothyroxine can be taken once daily and has a 7-day half-life, providing stable plasma levels and satisfactory results for the vast majority of patients. Liothyronine on the other hand is more rapidly metabolised, necessitating thrice daily administration [20].

Liothyronine is more potent than levothyroxine and has a more rapid onset of action. For this reason, liothyronine has been used in certain situations for patients with hypothyroidism such as myxoedematous coma. The short duration of action of liothyronine has also been useful for thyroid hormone replacement in patients having undergone thyroidectomy for thyroid cancer until they have received radioiodine [21]. Liothyronine has been successfully used in thyroidectomy patients to prevent rapidly progressive hypothyroidism, leading to respiratory failure [22]. Liothyronine has been shown to be of benefit as a pre-operative treatment in patients undergoing heart valve surgery, to prevent precipitation of post-operative hypothyroidism [23]. There is some evidence to suggest that there is less recurrence of hyperthyroidism after anti-thyroid treatment in Grave's disease, when liothyronine is used as replacement therapy instead of levothyroxine [24]. Furthermore, there have been cases where liothyronine has been shown to be of benefit when given perioperatively to patients with central hypothyroidism, due to pituitary tumours [25]. Also, for some time, psychiatrists have been aware of the role of liothyronine as an adjunct treatment in resistant bipolar depression [26, 27].

\section{Clinical Evidence on Combination Therapy With Liothyronine and Levothyroxine}

There has been a great deal of debate about the benefits of liothyronine, either on its own or in combination with levothyroxine.

Liothyronine may have positive benefits, compared with levothyroxine. Celi et al [28] demonstrated that, while levothyroxine and liothyronine are equivalent in their biochemical effects on TSH levels, their effects on cardiovascular function and insulin sensitivity, liothyronine has a positive impact on lipid profiles and on weight reduction.

The use of liothyronine in combination with levothyroxine, however, would in theory, provide replacement in a more physiologic manner. Several studies have claimed that combination therapy has a more positive effect on depression, anxiety and quality of life than levothyroxine therapy alone $[29,30]$. Other studies have noted a reduction in total cholesterol and LDL cholesterol [13].

It has been suggested that certain patient types with polymorphism in deiodinase 2 and thyroid hormone transporter expression may do well on combination therapy [31]. This would explain the following observations:

1) that the addition of liothyronine to therapy in athyrotic patients is beneficial if they are not responsive to levothyroxine alone [32].

2) that combination treatment may be of benefit in children with congenital hypothyroidism, who experience persistent hypothyrotropinaemia despite good compliance with levothyroxine [33].

3) that so-called "low T3 syndrome", characterized by poor cardiac performance in patients with a reduced plasma T3 level, but normal TSH levels [30], appears to be a strong predictor of mortality in cardiac patients, and is linked to a poor prognosis in cardiovascular disease [34]. Liothyronine has been studied as short-term replacement therapy in patients with dilated cardiomyopathy, leading to improved ventricular performance and neuroendocrine profile [35].

A meta-analysis of 11 studies of combination therapy [36] demonstrated that there was no clear benefit of combination therapy, compared to levothyroxine therapy alone. It has however, been suggested that studies of levothyroxine and liothyronine combinations were not adequately powered to detect and evaluate changes in psychological well-being [37], and that the review may have compared studies with different patient groups and outcomes [13]. Larger controlled studies may therefore be required to fully understand the benefit of liothyronine in combination with levothyroxine.

Despite the meta-analysis data suggesting that there are no clear benefits from combined therapy, there may be emerging evidence to suggest that certain subgroups of patients will respond well to addition of liothyronine to levothyroxine therapy. Clearly further research is required to es- 
tablish which groups of patients these are.

There are several conditions related to thyroid dysfunction other than the clinical hypothyroidism for which there may be a role for treatment with T3. Furthermore, there is some evidence that the standard treatment of hypothyroidism with levothyroxine may not always be effective, and therefore, there may be a role for liothyronine instead of, or in combination with, levothyroxine. Further work is required to characterize which patients might benefit from this approach.

\section{Key Points}

1) Hypothyroidism has a gradual onset and non-specific symptoms, which might be subtle, and which might therefore be ignored or misdiagnosed.

2) Subclinical hypothyroidism is a well-established phenomenon where a patient does not have thyroid symptoms, but shows biochemical evidences of hypothyroidism. However, diagnosis and treatment of these patients may prevent development of overt hypothyroidism and cardiovascular symptoms.

3) Replacement therapy with levothyroxine (T4) is the treatment of choice for hypothyroidism; levothyroxine is taken daily, provides stable plasma levels and is suitable for the majority of patients.

4) Patients with certain forms of hypothyroidism - central hypothyroidism, thyroidectomy patients and patients with "low T3 syndrome" - may benefit from treatment with liothyronine (T3), which is more potent and has a shorter onset of action.

5) The use of liothyronine in combination with levothyroxine is controversial, but there is evidence that some patients, particularly those with deiodinase 2 and thyroid hormone transporter expression polymorphisms, may benefit from combination therapy.

\section{Declaration}

This paper activity has been initiated, funded and reviewed by Amdipharm Mercury Company Ltd.

\section{References}

1. Lloyd J, Yerbury P, Ruzala V. Thyroid disorders: clinical features and diagnosis. Clin Pharm. 2011;3:323-324, $326,329$.

2. Canaris GJ, Manowitz NR, Mayor G, Ridgway EC. The Colorado thyroid disease prevalence study. Arch Intern Med. 2000;160(4):526-534.
3. Caldwell G, Kellett HA, Gow SM, Beckett GJ, Sweeting VM, Seth J, Toft AD. A new strategy for thyroid function testing. Lancet. 1985;1(8438):1117-1119.

4. de los Santos ET, Starich GH, Mazzaferri EL. Sensitivity, specificity, and cost-effectiveness of the sensitive thyrotropin assay in the diagnosis of thyroid disease in ambulatory patients. Arch Intern Med. 1989;149(3):526532.

5. Klee GG, Hay ID. Biochemical testing of thyroid function. Endocrinol Metab Clin North Am. 1997;26(4):763775.

6. Hollowell JG, Staehling NW, Flanders WD, Hannon WH, Gunter EW, Spencer CA, Braverman LE. Serum TSH, T(4), and thyroid antibodies in the United States population (1988 to 1994): National Health and Nutrition Examination Survey (NHANES III). J Clin Endocrinol Metab. 2002;87(2):489-499.

7. Huber G, Staub JJ, Meier C, Mitrache C, Guglielmetti M, Huber P, Braverman LE. Prospective study of the spontaneous course of subclinical hypothyroidism: prognostic value of thyrotropin, thyroid reserve, and thyroid antibodies. J Clin Endocrinol Metab. 2002;87(7):32213226.

8. Vanderpump MP, Tunbridge WM, French JM, Appleton D, Bates D, Clark F, Grimley Evans J, et al. The incidence of thyroid disorders in the community: a twentyyear follow-up of the Whickham Survey. Clin Endocrinol (Oxf). 1995;43(1):55-68.

9. Parle JV, Franklyn JA, Cross KW, Jones SC, Sheppard MC. Prevalence and follow-up of abnormal thyrotrophin (TSH) concentrations in the elderly in the United Kingdom. Clin Endocrinol (Oxf). 1991;34(1):77-83.

10. Biondi B, Klein I. Hypothyroidism as a risk factor for cardiovascular disease. Endocrine. 2004;24(1):1-13.

11. Bauer M, Heinz A, Whybrow PC. Thyroid hormones, serotonin and mood: of synergy and significance in the adult brain. Mol Psychiatry. 2002;7(2):140-156.

12. Saravanan P, Visser TJ, Dayan CM. Psychological well-being correlates with free thyroxine but not free 3,5,3'-triiodothyronine levels in patients on thyroid hormone replacement. J Clin Endocrinol Metab. 2006;91(9):3389-3393.

13. Fadeyev VV, Morgunova TB, Melnichenko GA, Dedov, II. Combined therapy with L-thyroxine and L-triiodothyronine compared to L-thyroxine alone in the treatment of primary hypothyroidism. Hormones (Athens). 2010;9(3):245-252.

14. Bach-Huynh TG, Nayak B, Loh J, Soldin S, Jonklaas J. Timing of levothyroxine administration affects serum thyrotropin concentration. J Clin Endocrinol Metab. 2009;94(10):3905-3912.

15. Bolk N, Visser TJ, Nijman J, Jongste IJ, Tijssen JG, Berghout A. Effects of evening vs morning levothyroxine intake: a randomized double-blind crossover trial. 
Arch Intern Med. 2010;170(22):1996-2003.

16. Ruchala M, Szczepanek-Parulska E, Zybek A. The influence of lactose intolerance and other gastro-intestinal tract disorders on L-thyroxine absorption. Endokrynol Pol. 2012;63(4):318-323.

17. Sharma R, Sharma TK, Kaushik GG, Sharma S, Vardey SK, Sinha M. Subclinical hypothyroidism and its association with cardiovascular risk factors. Clin Lab. 2011;57(9-10):719-724.

18. McDermott MT, Ridgway EC. Subclinical hypothyroidism is mild thyroid failure and should be treated. J Clin Endocrinol Metab. 2001;86(10):4585-4590.

19. Boelen A, Kwakkel J, Fliers E. Beyond low plasma T3: local thyroid hormone metabolism during inflammation and infection. Endocr Rev. 2011;32(5):670-693.

20. Lloyd J, Yerbury P, Ruzala V. Thyroid disorders: management. Clin Pharm. 2011;3:330-332, 335-337.

21. Ben-Shachar R, Eisenberg M, Huang SA, DiStefano JJ, 3rd. Simulation of post-thyroidectomy treatment alternatives for triiodothyronine or thyroxine replacement in pediatric thyroid cancer patients. Thyroid. 2012;22(6):595-603.

22. Finsterer J, Prainer C, Stollberger C, Valentin A, Jarius C, Schreier R. Hypothyroidism and muscular respiratory failure successfully treated with liothyronine. South Med J. 2002;95(11):1347-1349.

23. Choi YS, Kwak YL, Kim JC, Chun DH, Hong SW, Shim JK. Peri-operative oral triiodothyronine replacement therapy to prevent postoperative low triiodothyronine state following valvular heart surgery. Anaesthesia. 2009;64(8):871-877.

24. Mastorakos G, Doufas AG, Mantzos E, Mantzos J, Koutras DA. T4 but not T3 administration is associated with increased recurrence of Graves' disease after successful medical therapy. J Endocrinol Invest. 2003;26(10):979-984.

25. Venkatesan T, Thomas N, Ponniah M, Khan D, Chacko AG, Rajshekhar V. Oral triiodothyronine in the perioperative management of central hypothyroidism. Singapore Med J. 2007;48(6):555-558.

26. Kelly T, Lieberman DZ. The use of triiodothyronine as an augmentation agent in treatment-resistant bipolar II and bipolar disorder NOS. J Affect Disord. 2009;116(3):222-226.

27. Carvalho AF, Machado JR, Cavalcante JL. Augmentation strategies for treatment-resistant depression. Curr Opin Psychiatry. 2009;22(1):7-12.

28. Celi FS, Zemskova M, Linderman JD, Smith S, Drinkard B, Sachdev V, Skarulis MC, et al. Metabolic effects of liothyronine therapy in hypothyroidism: a randomized, double-blind, crossover trial of liothyronine versus levothyroxine. J Clin Endocrinol Metab. 2011;96(11):34663474.

29. Nygaard B, Jensen EW, Kvetny J, Jarlov A, Faber J. Effect of combination therapy with thyroxine (T4) and 3,5,3'-triiodothyronine versus T4 monotherapy in patients with hypothyroidism, a double-blind, randomised cross-over study. Eur J Endocrinol. 2009;161(6):895902.

30. Valizadeh M, Seyyed-Majidi MR, Hajibeigloo H, Momtazi S, Musavinasab N, Hayatbakhsh MR. Efficacy of combined levothyroxine and liothyronine as compared with levothyroxine monotherapy in primary hypothyroidism: a randomized controlled trial. Endocr Res. 2009;34(3):80-89.

31. Wiersinga WM. Do we need still more trials on T4 and T3 combination therapy in hypothyroidism? Eur J Endocrinol. 2009;161(6):955-959.

32. Solter D, Solter M. Benefit of combined triiodothyronine (LT(3)) and thyroxine (LT(4)) treatment in athyreotic patients unresponsive to LT(4) alone. Exp Clin Endocrinol Diabetes. 2012;120(2):121-123.

33. Strich D, Naugolny L, Gillis D. Persistent hyperthyrotropinemia in congenital hypothyroidism: successful combination treatment with levothyroxine and liothyronine. J Pediatr Endocrinol Metab. 2011;24(5-6):347350.

34. Iervasi G, Pingitore A, Landi P, Raciti M, Ripoli A, Scarlattini M, L'Abbate A, et al. Low-T3 syndrome: a strong prognostic predictor of death in patients with heart disease. Circulation. 2003;107(5):708-713.

35. Pingitore A, Galli E, Barison A, Iervasi A, Scarlattini M, Nucci D, L'Abbate A, et al. Acute effects of triiodothyronine (T3) replacement therapy in patients with chronic heart failure and low-T3 syndrome: a randomized, placebo-controlled study. J Clin Endocrinol Metab. 2008;93(4):1351-1358.

36. Grozinsky-Glasberg S, Fraser A, Nahshoni E, Weizman A, Leibovici L. Thyroxine-triiodothyronine combination therapy versus thyroxine monotherapy for clinical hypothyroidism: meta-analysis of randomized controlled trials. J Clin Endocrinol Metab. 2006;91(7):2592-2599.

37. Saravanan P, Simmons DJ, Greenwood R, Peters TJ, Dayan CM. Partial substitution of thyroxine (T4) with tri-iodothyronine in patients on T4 replacement therapy: results of a large community-based randomized controlled trial. J Clin Endocrinol Metab. 2005;90(2):805812 . 